\title{
(Non)luminescent properties of iron compounds
}

\author{
Jozef Šima \\ Institute of Inorganic Chemistry, Technology and Materials, FCHPT STU, \\ Radlinského 9, 81237 Bratislava, Slovakia \\ jozef.sima@stuba.sk
}

\begin{abstract}
This mini-review evaluates deactivation processes of iron-containing species and substances in solutions and the solid state with the focus on radiation deactivations from their electronically excited states. Theoretical and practical aspects of luminescence are assessed and conclusions based on up-to-date experimental data are formulated.
\end{abstract}

Keywords: iron compounds, luminescence, nonradiative deactivations, photochemistry

\section{Introduction}

When dealing with photodeactivation processes of electronically excited iron-containing species and substances it should be worth summarizing and reminding three aspects of the issue.

The first one is devoted to the relation of the rate constant of electronic deactivations (transitions lowering the electronic energy) and rotationalvibrational relaxation (lowering mainly vibrational energy within a given electronic state). In the history of photochemistry two limiting approaches to this relation have evolved. The first approach may be illustrated by the Jablonski diagrams (Jablonski, 1933), later elaborated by Adamson (Adamson, 1976) who introduced the term "thexi-state" to characterize the state thermally equilibrated with its surroundings by the transfer of part of vibrational energy of a populated excited state to surrounding molecules through their collisions. The Adamson's concept was based on the assumption that thermal equilibration (i.e. vibrational relaxation) preceded electronic deactivation processes of excited molecules. It is worth noting that his concept was formulated before introducing ultrafast flash-techniques (working in nano-, pico- and femtosecond time domain) into photochemistry and photophysics. Adamson applied his concept mainly in the field of photochemistry of coordination compounds. The advent and introduction of the mentioned ultrafast techniques has documented that situation could be diverse, i.e. electronic deactivation is frequently a faster process that vibrational relaxation.

The second aspect is stemming from the fact that neither iron(II) nor iron(III) coordination compounds undergo at normal conditions radiation deactivations. Authors of the comprehensive papers reviewing luminescence of transition metal complexes (Fleishauer and Fleishauer, 1970; Yam and Wong, 2011) have characterized iron complexes as non-luminescent.

The third aspect covers newly emerging substances/ systems and experimental techniques. As for the systems, nanoparticles containing elemental iron or its compounds, and their impact (quenching, inducing, enhancing and shifting) on luminescence of other parts of the systems may be offered. The newly emerging techniques may be exemplified by e.g. femtosecond powder X-ray diffraction (Freyer et al., 2013). Both the newly developed systems and techniques have contributed to the theoretical knowledge in the field of photochemistry and photophysics and to practical applications of the acquired knowledge.

This mini-review is aimed at providing basic information on the existence of the phenomenon of luminescence in individual kinds of iron-containing substances and examples on the situation in the field of radiative deactivation of such substances.

\section{Luminescence as deactivation mode}

Any electronically excited species, irrespective of the mode of its formation (photoexcitation, energy transfer, chemical reaction, etc.) undergoes deactivation. The scheme of deactivation modes is illustrated in Fig. 1.

The three upper modes are monomolecular photophysical deactivations, namely nonradiative internal conversion IC (preserving multiplicity) andintersystem crossing ISC (changing multiplicity, usually by \pm 2 ); radiative deactivation (fluorescence without changing the multiplicity or phosphorescence with multiplicity change usually by \pm 2 ); nonradiative transfer to the ground state manifested itself as heat evolving. Further four modes are analogous bimolecular processes with the participation of a quencher $\mathrm{Q}$. The two last modes are photochemical deactivations. $[\mathrm{A}-\mathrm{Q}]^{*}$ may denote also an exciplex or excimer. 


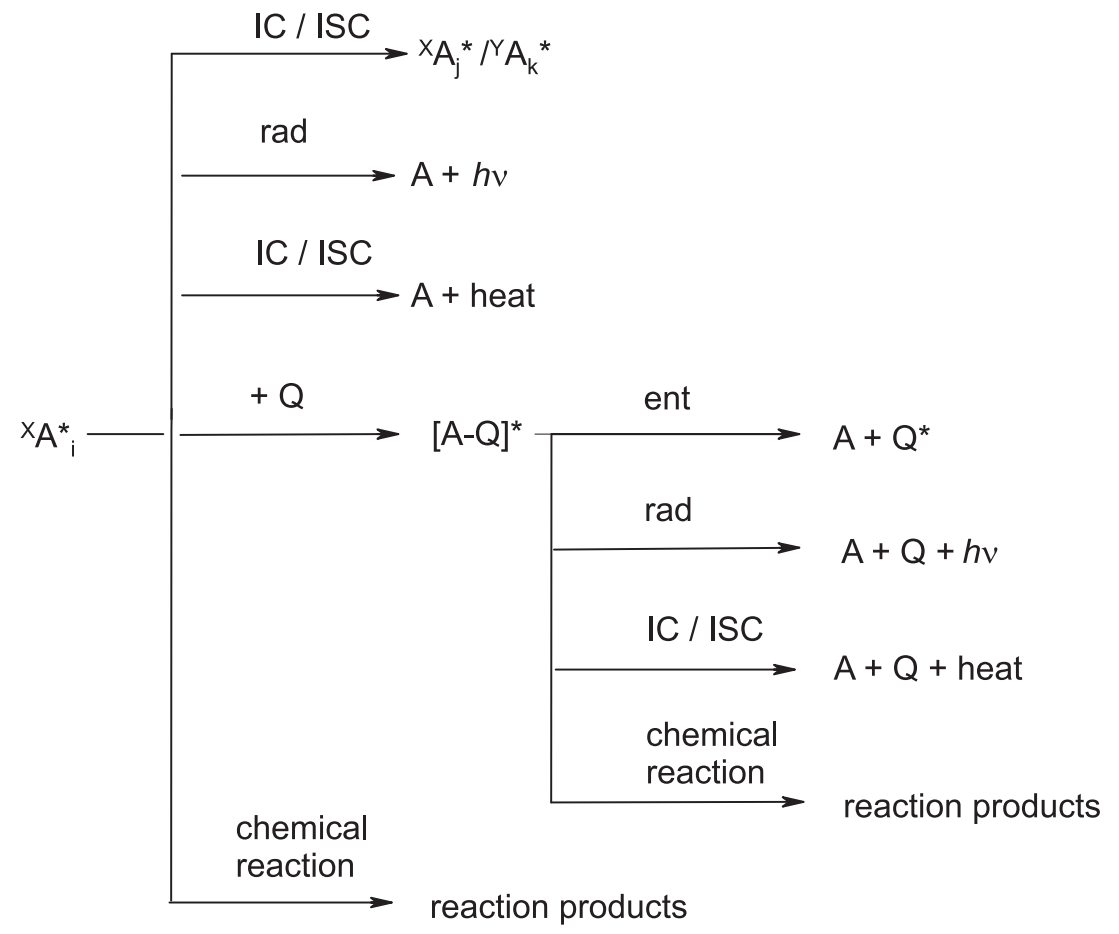

Fig. 1. Scheme of deactivation modes of electronically excited species $A *$ ( $\mathrm{rad}=$ radiative deactivation; $\mathrm{IC}=$ internal conversion; ISC = intersystem crossing; ent = energy transfer; $\mathrm{X}$ and $\mathrm{Y}=$ multiplicity,

$\mathrm{i}, \mathrm{j}, \mathrm{k}=$ individual excited states).

In general, luminescence is spontaneous emission of radiation from an electronically excited species or from a vibrationally excited species not in thermal equilibrium with its environment. This term covers thus both phosphorescence and fluorescence (Braslavsky, 2007).

\section{Elemental iron}

The emission of radiation (line spectra) from the "free" excited iron atom and its cations is a wellknown phenomenon utilized, e.g. in analytical determination of iron by inductively coupled plasma atomic emission spectroscopy (Sansonetti and Martin 2995; Kramida et al., 2014), mainly through emission lines at 259.940 and $238.20 \mathrm{~nm}$.

At the interface of elemental iron and its compounds, iron nanoparticles containing a few iron atoms in oxidation state 0 may be located. The superparamagnetic luminescent cations $\left[\mathrm{Fe}_{10}(\mathrm{TOPO})_{3}\left(\mathrm{H}_{2} \mathrm{O}\right)_{3}\right]^{+}, \quad\left[\mathrm{Fe}_{13}(\mathrm{TOPO})_{2}\left(\mathrm{H}_{2} \mathrm{O}\right)\right]^{+}$and $\left[\mathrm{Fe}_{8}(\mathrm{TOPO})\left(\mathrm{H}_{2} \mathrm{O}\right)_{2}\right]^{+}$having the $\mathrm{Fe}_{\mathrm{n}}$ core were detected by mass spectrometry in solution in the presence of tri-octylphosphineoxide (TOPO). The quantum yield of luminescence centered at $565 \mathrm{~nm}$ reached $10 \%$ (Goswami et al., 2014).

\section{Systems doped with iron and its ions}

Luminescence occurring in the form of multiphoton emission process was proposed as a deactivation channel in some $\mathrm{Fe}^{2+}$-doped semiconducting materials. The radiative and nonradiative kinetics of ${ }^{5} \mathrm{~T}_{2} \rightarrow{ }^{5} \mathrm{E}$ transition in $\mathrm{Fe}^{2+}$ ions acting as dopant in GaAs, GaP, InP, CdS and $\mathrm{ZnS}$ revealed that the luminescence time decay is of order of some microseconds, and both the radiative and nonradiative transition rate constants are of the order $10^{4} \mathrm{~s}^{-1}$ (Podlowski et al., 1994).

Several authors (Varney et al., 2011; Rotman et al., 1989) observed a strong near-infrared luminescence (centered at about $800 \mathrm{~nm}$ ) of both undoped YAG single crystals and those doped with $\mathrm{Fe}^{3+}$ ions. The luminescence was attributed to both the presence of $\mathrm{Fe}^{3+}$ ions and native defects. As part of the processes, the absorption of radiation by $\mathrm{Fe}^{3+}$ ions as well as energy transfer processes are involved. Neither kinetic data nor the spectral nature of the luminescence were provided.

A characteristic infrared luminescence band, dominated by a zero-phonon line at $1.30 \mathrm{eV}$ has been detected in gallium nitride $(\mathrm{GaN})$ epitaxial layers (Baur et al., 1994) and assigned to the intra- $3 d$-shell transitions ${ }^{4} \mathrm{~T}_{1}(\mathrm{G}) \rightarrow{ }^{6} \mathrm{~A}_{1}(\mathrm{~S})$ of $\mathrm{Fe}^{3+}$ trace impurities. Another infrared emission is often also observed at $1.19 \mathrm{eV}$. This is, however, tentatively assigned to $\mathrm{Cr}^{4+}$ trace impurities. Based on the measured data, the role of iron and chromium as minority-carrier lifetime killers in GaN-based optoelectronic devices was suggested.

A luminescence band at $770 \mathrm{~nm}$ due to iron centres has been observed in lithium niobate crystals treated 
at $520^{\circ} \mathrm{C}$ in lithium carbonate (Parsons et al., 1975). Without this treatment only a broad background luminescence was observed. The main effect of the treatment is a reduction of iron centres to the $\mathrm{Fe}^{2+}$ state but some evidence was found that destruction of shallow traps leading to the luminescence increasing was also involved.

It was found that $\mathrm{TiO}_{2}$ when doped with iron present in the form of $\mathrm{Fe}^{3+}$ ions provide luminescence (Nasralla et al., 2013). The photoluminescence spectrum of $\mathrm{TiO}_{2}$ containing $5 \%$ Fe calcined at $400{ }^{\circ} \mathrm{C}$ shows an emission peak at around $438 \mathrm{~nm}$ when excited at $250 \mathrm{~nm}$. This active band could be due to the bound excitons. By increasing the temperature, the photoluminescence intensity decreases due to an increase of nonradiative transition(s), and peak positions of the photoluminescence are shifted towards the longer wavelength. Increasing iron concentration, the nonradiative decay process become dominant, which was attributed to the concentration quenching process of Stern-Volmer type.

Kulyuk investigated magnetic and luminescence properties of iron-doped ZnSe crystals (Kulyuk et al., 2010). The oxidation state of iron is an open question. The authors declared that iron was responsible for photoluminescence bands at 980, 1320, $1450 \mathrm{~nm}$ and quenched luminescence band at $630-645 \mathrm{~nm}$. Iron is thus a quencher of visible luminescence in zinc selenide which is identical effect as that observed in above mentioned case of iron-doped $\mathrm{TiO}_{2}$ (Nasralla et al., 2013). In none of the mentioned papers radiative deactivation and relaxation rate constants were determined.

When present in minerals, the ion $\mathrm{Fe}^{2+}$ is the strongest visible luminescence quencher, but it has an emission band in the IR part of the spectrum (Gaft et al., 2005). As for luminescence of $\mathrm{Fe}^{3+}$, because of the large value of crystal field, the emission is shifted into the deep red when $\mathrm{Fe}^{3+}$ is present on tetrahedral sites. $\mathrm{Fe}^{3+}$ in octahedral coordination is predicted to emit in the near IR at about 900 to $1,000 \mathrm{~nm}$, but was not confidently observed in minerals. Steady-state luminescence of $\mathrm{Fe}^{3+}$ in minerals is mainly observed when it substitutes for $\mathrm{Al}^{3+}$ or $\mathrm{Si}^{4+}$ in tetrahedral sites in aluminosilicates. The luminescent transitions are forbidden and correspondingly the decay times are rather long ( Gaft et al., 2005).

\section{Systems of semiconducting nanoparticles containing surface-anchored iron complexes}

This category of luminescent substances can be exemplified by titanium dioxide with hematoporphyrin, HP or iron(III) hematoporphyrin, Fe(III) HP attached to its surface (Sardar et al., 2013, 2014). It was found that the intensity of the fluorescence from HP is strongly reduced both by Fe(III) and $\mathrm{TiO}_{2}$. The reason is an efficient electron transfer from $\mathrm{HP}$ to $\mathrm{Fe}(\mathrm{III})$ and/or $\mathrm{TiO}_{2}$. In case of these systems also lifetimes and nonradiative deactivation rate constants were determined. Dynamics of picosecond-resolved luminescence transients of HP, $\mathrm{Fe}(\mathrm{III}) \mathrm{HP}, \mathrm{HP}-\mathrm{TiO}_{2}$ and $\mathrm{Fe}(\mathrm{III}) \mathrm{HP}-\mathrm{TiO}_{2}$ nanohybrids can be expressed through the average lifetime values (in ns), 11.39, 3.38, 1.96 and 1.19 clearly documenting a quenching impact of $\mathrm{TiO}_{2}$ and $\mathrm{Fe}(\mathrm{III})$ on the HP luminescence.

\section{Iron oxides (nanoparticles) containing systems}

In this area, a few kinds of iron oxide nanoparticles with luminescent molecules attached to their surface have been investigated. A suitable example of the case is represented by 5-amino-1,10-phenanthroline (Aphen)-functionalized superparamagnetic $\mathrm{Fe}_{3} \mathrm{O}_{4}$ nanoparticles where Aphen acts as a luminescence source (Govindaiah et al., 2010). Since the magnetic core (nanoparticles of a metal or an oxide) normally quenches the fluorescence of functionalized chromophore, the authors eliminated the problem by covalent bonding of chromophore (phen) to the magnetic nanoparticle via a spacer ( $\mathrm{NH}_{2}$-group) obtaining thus a system providing the luminescence with the quantum yield about 0.035 at room temperature. Aphen-functionalized magnetic $\mathrm{Fe}_{3} \mathrm{O}_{4}$ nanoparticles showed an emission peak at $448 \mathrm{~nm}$, which is shifted significantly to the blue region compared with the emission spectrum of pure Aphen $\left(\lambda_{\text {em }}=494 \mathrm{~nm}\right)$. This blue shift indicates that Aphen is anchored onto the surface of the $\mathrm{Fe}_{3} \mathrm{O}_{4}$ nanoparticles.

As part of research on the synthesis, structure, properties and application possibilities of $\mathrm{Fe}_{3} \mathrm{O}_{4}$, also photoluminescence properties of the oxide were investigated (Goswami et al., 2014a). It was demonstrated that tartrate-functionalized $\mathrm{Fe}_{3} \mathrm{O}_{4}$ nanoparticles exhibited ligand-to-metal charge transfer (LMCT) transition in the UV spectral region and excellent blue fluorescence $\left(\lambda_{\text {em }}=440 \mathrm{~nm}\right)$ which might originate from LMCT states. This is a difference from the previous system where the luminescence was attributed to intraligand transition in the Aphen ligand.

Nanocrystals of $\gamma-\mathrm{Fe}_{2} \mathrm{O}_{3}$ with pyrene derivatives anchored to their surface are luminescent, the luminescence originating from pyrenes (Turro et al., 2002). The lifetime of pyrene fluorescence reached a few ns under aerated conditions and was not changed by $\gamma-\mathrm{Fe}_{2} \mathrm{O}_{3}$, its intensity, however, decreased when increasing $\gamma-\mathrm{Fe}_{2} \mathrm{O}_{3}$ concentration.

Within the study of solid phase redox processes an electron transfer from the luminescent dye 2',7'-dichlorofluorescein anchored to $\alpha-\mathrm{Fe}_{2} \mathrm{O}_{3}$ (hematite) or 
$\mathrm{FeO}(\mathrm{OH})$ nanoparticles was followed (Gilbert et al., 2013). Photoexcitation of the dye-sensitized nanoparticles leads to complicated dynamics interpreted as a combination of band-gap excitations of the iron oxides and dye excitation and its deactivation due to luminescence, electron transfer and energy transfer processes. Based on a detailed analysis of transient absorption spectra and fluorescence measurement it was found that the decay of the stimulated emission of the dye occurred with a time constant less than $300 \mathrm{fs}$ in all investigated samples. It was found that "free" dye exhibits strong fluorescence, however, when surface-bound to iron-containing nanoparticles, the dye fluorescence is quenched.

\section{Coordination compounds}

Luminescent iron complexes can be, in principle, either iron-containing "free" molecules and ions or molecules attached to the surface of (nano)particles, usually of a semiconducting compound.

As for "free" iron complexes, luminescence is a very rare phenomenon and in cases of kinetically labile, high-spin complexes it might be disputed and explained as occurring from free ligand.

Investigating photophysics of iron(II) polypyridine chelates it has been found that low-spin (LS) singlet to high-spin (HS) quintet transition can be photoinduced through a simple ultrafast cascade ${ }^{1}$ MLCT $\rightarrow$ ${ }^{3} \mathrm{MLCT} \rightarrow{ }^{5} \mathrm{~T}_{2}$ occurring in less than $300 \mathrm{fs}$ (Juban et al., 2006; Bressler et al., 2009), bypassing low-lying LF states. It was documented (Galle et al., 2013) that there is also a possibility to accomplish reversal $\mathrm{HS} \rightarrow$ LS transitions through excitation with selective radiation wavelength. As for objects, $\left[\mathrm{Fe}(\mathrm{phen})_{3}\right]^{2+}$ and $\left[\mathrm{Fe}\left(2-\mathrm{CH}_{3} \text {-phen }\right)_{3}\right]^{2+}$ complexes in solution were investigated. In case of the complexes in acetonitrile, the ${ }^{5}$ MLCT is formed by photoexcitation at about $500 \mathrm{~nm}$ within $300 \mathrm{fs}$ and its relaxation lasts some nanoseconds. The reverse $\mathrm{HS} \rightarrow \mathrm{LS}$ process is achieved by irradiation of the HS complexes at about $300 \mathrm{~nm}$. Within the both excitation modes, MLCT states were populated and the issue of LF states involvement was open. The results obtained in the field of the kinetics of deactivation processes in iron(II) polypyridine complexes are thoroughly assessed and compared to analogous ruthenium(II) complexes (Chergui, 2013). As a general finding it was concluded that the lowest excited (HS) quintet state relaxed nonradiatively to the LS ground state with times ranging from about $0.65 \mathrm{~ns}$ to $150 \mathrm{~ns}$ in room temperature solutions.

A detailed photophysical study of $\left[\mathrm{Fe}\left(\operatorname{tren}(\mathrm{py})_{3}\right)\right]^{2+}$ $\left(\operatorname{tren}(\mathrm{py})_{3}=\operatorname{tris}(2\right.$-pyridylmethyliminoethyl)amine $)$ revealed (Monat and McCusker, 2000) that the HS state was formed in about $300 \mathrm{fs}$. The authors also observed additional dynamics attributed to vibrational relaxation in the ${ }^{5} \mathrm{~T}_{2}$ state with a time constant of $8 \pm 2$ ps. Information concerning dynamics associated with the initially formed MLCT state was also unravelled by monitoring spectral changes in regions where the difference spectra for the MC and MLCT states are of opposite sign. The authors thus concluded that depopulation of the MLCT manifold occurs in $80 \pm 20$ fs. Contrary to their ruthenium analogues, Fe(II)-polypyridine complexes do not exhibit a long-lived ${ }^{3}$ MLCT phosphorescence since their LF states lie at lower energies than the MLCT states. On the other hand, the ultrafast relaxation processes occurring in the manifold of ${ }^{1}$ MLCT states of $\left[\mathrm{Fe}(\mathrm{bpy})_{3}\right]^{2+}$ that lead to a mirror-like image (with respect to the absorption band) fluorescence were estimated to occur in $<10 \mathrm{fs}$ and were attributed to intramolecular vibrational redistribution (IVR) and internal conversion (IC) processes (Consani et al. 2009).

Working with $\left[\mathrm{Fe}(\mathrm{bpy})_{3}\right]^{2+}$ (Gawelda et al., 2007a) a weak emission was observed at $\geq 650 \mathrm{~nm}$ and $t \geq 100$ fs. The comparison of Raman and emission time traces allowed the authors to extract an exponential decay of $30 \pm 10$ fs for the ${ }^{1}$ MLCT fluorescence. The weaker emission at about $660 \mathrm{~nm}$ was found to decay in $130 \mathrm{fs}$ and is assigned to the ${ }^{3}$ MLCT state. Indeed, it lies in the wavelength range where the ${ }^{3}$ MLCT phosphorescence is expected to occur. These results represent the first observation of fluorescence and phosphorescence of $\mathrm{Fe}$ (II) spin-crossover complexes. Interestingly, the decay of the ${ }^{3} \mathrm{MLCT}$ state in $\left[\mathrm{Fe}(\mathrm{bpy})_{3}\right]^{2+}$ is comparable to the value of $80 \pm 20 \mathrm{fs}$ reported for $\left[\mathrm{Fe}\left(\operatorname{tren}(\mathrm{py})_{3}\right)\right]^{2+}$ (Monat et al., 2000).

Turning back to the Adamson's conception described above it might be worth introducing also some data on kinetics of vibrational relaxation. In several papers discussed in the review (Chergui, 2013) it is stated that as for the quintet (HS) state of iron(II) complexes, the analysis of time-resolved spectra leads to two time values. The femtosecond component is attributed to electronic changes, the picosecond component is associated with vibrational cooling within a given electronically excited state. Luminescence of an iron(II) complex was detected by Braem (Braem et al., 2012) who investigated pump wavelength dependence of the fluorescence of aqueous $\left[\mathrm{Fe}(\mathrm{bpy})_{3}\right]^{2+}$. The ${ }^{1} \mathrm{MLCT}$ fluorescence appears at zero time delay with a mirror-like image with respect to the absorption and decays in $\leq 30-45$ fs due to intersystem crossing to the ${ }^{3}$ MLCT states. The very early dynamics are characterized by internal conversion (IC) and intramolecular vibrational redistribution (IVR) processes on a time scale estimated to $\leq 10 \mathrm{fs}$ using the ${ }^{1}$ MLCT lifetime as an internal clock. 
LS $\leftrightarrow$ HS light-induced excited spin state trapping (LIESST) effect was investigated for the spin-crossover $\left[\mathrm{Fe}(\mathrm{ptz})_{6}\right]\left[\mathrm{BF}_{4}\right]_{2}$, where ptz $=1$-propyltetrazole, performing excitation into LF bands (Marino et al., 2014). The complex is interesting since it have no low-lying LMCT states and allows to inspect in more detail the role of LF states in LIESST processes. It was found that the role of LF states should not be neglected and the reverse $(\mathrm{HS} \rightarrow \mathrm{LS}$ ) process was achieved irradiating the complex into spinallowed LF bands. It was deduced that the ultrafast reverse-LIESST pathway involved the lowest energy $\mathrm{S}=1 \mathrm{LF}$ state as an intermediate state with a lifetime of 39 ps for the light-induced HS $\rightarrow$ LS conversion on irradiation into the spin-allowed LF transition of the high-spin species in the NIR. No luminescence is mentioned in the paper.

Relation between an ultrafast electronic deactivation and a much slower vibrational relaxation was found also for iron(III) complexes. As an example, the low-spin $\left[\mathrm{N}_{3}-\mathrm{Fe}(\text { cyclam-acetato })\right]^{2+}$ complex can be introduced (Vennekate et al., 2012) with vibrational cooling as a slower process (13 ps) and a faster internal conversion to the electronic doublet ground state lasting 2 ps.

As for high-spin iron(III) complexes, a blue luminescence (400-450 nm) was claimed (Basu et al., 2007) to be observed for $\left[\mathrm{Fe}\left(\mathrm{HL}^{1}\right)_{2}\right] \mathrm{Cl},\left[\mathrm{Fe}\left(\mathrm{L}^{2}\right)_{2}\right] \mathrm{Cl}$, and $\left[\mathrm{Fe}\left(\mathrm{MeL}^{1}\right)_{2}\right] \mathrm{Cl}$ with interlayer $\mathrm{O}-\mathrm{H} \cdots \mathrm{Cl}$ bridging ( $\mathrm{HL}^{1}, \mathrm{~L}^{2}$, and $\mathrm{MeL}^{1}$ are tridentate $\mathrm{N}_{2} \mathrm{O}$-ligands). It should, however, be pointed out that these iron(III) complexes are kinetically labile and the luminescence of the ligands and complexes are very similar, i.e. it might happen that the luminescence is of intraligand kind and does not involve the orbitals of the iron(III) central atom. Moreover, the ligand and its iron(III) complex undergo photoinduced intramolecular azo-imine tautomerism.

Photoluminescence was declared (Kong et al., 2011) to occur from excited spindle-like tris(8-hydroxyquinoline) iron $\left(\mathrm{FeQ}_{3}\right)$ complex. It is blue shifted when compared to the ligand. It should be pointed out, however, that the molecular formula of the product is only speculated without full determination of its composition and structure. Moreover, the authors did not specify even the oxidation state of the central atom.

\section{Conclusions}

Based on the above data it follows that iron compounds can be grouped, from the viewpoint of luminescence, into three classes.

Free iron atoms and ions, iron-containing nanoparticles, and substances doped with iron and its ions provide emission from their excited states. It is generally observed that iron group elements act as a "killer of luminescence" by means of resonance energy transfer as documented by investigating several phosphors. On the other hand, infrared luminescence due to intraions (LF) transitions in $\mathrm{Fe}^{2+}$ and $\mathrm{Fe}^{3+}$ ions is found (Yen et al., 2006).

Iron-containing nanoparticles with luminescent surface-anchored molecules are luminescent, their luminescence originates, however, from the anchored molecules. In this class of substances the presence of iron supresses the luminescence of anchored molecules.

The most unusual observations relates to nonluminescent behaviour of the majority of iron complexes. To understand and explain this fact, several hypotheses may be offered.

One of them stems from rate constants of deactivation processes. If the excited state directly reached by irradiation gives rise to $x$ primary processes, the quantum yield of a specific process (e.g. of radiative deactivation) is given by the ratio of the rate constant of that process (e.g. $k_{\mathrm{r}}$ ) to the sum of the rate constants of all the $x$ processes which deactivate the excited state (Balzani and Carrasiti, 1970)

$$
\Phi_{r}=\frac{k_{r}}{\sum_{x} k_{x}}
$$

Thus, if $k_{\mathrm{r}}$ is very low and the other, nonradiative physical and chemical deactivation modes (Fig. 1) occur with a very high rate constant, no luminescence might be observed. A nonluminescent behaviour of iron complexes can be, therefore, tentatively explained as a consequence of extremely fast competitive nonradiative deactivation processes which are in experimentally investigated cases much faster than vibrational relaxation $(\mathrm{Ju}-$ ban et al., 2006; McCusker et al., 1992; Poznyakov et al., 2004, 2006, 2006a, 2007; Šima et al., 2013; Freyer et al., 2013; Jeremy and McCusker, 2000; Khalil et al., 2006; Smeigh et al., 2008; Gawelda et al., 2006, 2007; Bressler et al., 2009; Conzani et al., 2009; Cannizzo et al., 2010). This approach, however, can be questioned due to a high sensitivity of luminescence measurement.

Another cause for finding the majority of iron compounds nonluminescent may lie in the selfabsorption of emitted radiation by a system (Ahn et al., 2007). This phenomenon happens in case of overlapping the wavelength of emitted radiation (luminescence) and absorption.

When dealing with deactivation process it should be worth reminding that the selection rules applying to spin-forbidden processes valid in the field of organic spectroscopy and photophysics do not work well for transition metal compounds. For example, 
not infrequently the rate constant of spin-forbidden intersystem crossing is higher than that for internal conversion (Juban et al., 2006). In spite of this fact, the impact of spin-forbiddeness and other selection rules applicable to transition-metal compounds on the luminescence efficiency cannot be ruled out.

\section{Acknowledgement}

The financial support of the Ministry of Education of the Slovak Republic through the VEGA grant No. 1/0543/15 is gratefully acknowledged.

\section{References}

Adamson AW (1976) Advances in Chemistry 150: 128-148.

Ahn T-S, AlKaysi RO, Müller AM, Wentz KM, Bardeen CJ (2007) Rev. Sci. Instruments 78: 086105.

Balzani V, Carrasiti V (1970) Photochemistry of Coordination Compounds. AP London, 9.

Basu Ch, Chowdhury S, Banerjee R, Stoeckli EH, Mukherjee S (2007) Polyhedron 26: 3617-3624.

Baur J, Maier K, Kunzer M, Kaufmann U, Schneider J, Amano H, Akasaki I, Detchprohm T, Hiramatsu K (1994) Appl. Phys. Lett. 64: 857-859.

Braem O, Messina F, El-Zohry AM, Cannizzo A, Chergui M (2012) Chem. Phys. 393: 51-57.

Braslavsky S (2007) Pure Appl. Chem. 79: 293-465.

Bressler C, Milne CJ, Pham V-T, ElNahhas A, van der Veen RM, Gawelda W, Johnson SL, Beaud B, Grolimund D, Kaiser M, Borca NC, Ingold G, Abela R, Chergui M (2009) Science 323: 489-492.

Cannizzo A, Milne CJ, Consani C, Gawelda W, Bressler C, van Mourik F, Chergui M (2010) Coord. Chem. Rev. 254: 2677-2686.

Chergui M (2013) In Spin-Crossover Materials, Properties and Application. (M.A. Halcrow, Ed.), Wiley 405-424.

Consani C, Prémont-Schwarz M, ElNahhas A, Bressler C, van Mourik F, Cannizzo A, Chergui M (2009) Angew. Chem. 121: 7320-7323.

Fleishauer PD, Fleishauer P (1970) Chem. Rev. 70 199-230.

Freyer B, Zamponi F, Juvé V, Stingl J, Woerner M, Elsaesser T, Chergui M (2013) J. Chem. Phys. 138: 144504.

Gaft M, Reisfeld R, Panzert G (2005) Modern Luminescence Spectroscopy of Minerals and Materials. Springer, Berlin: 200-208.

Galle G, Tribollet J, Jonusauskas G, Tondusson M, Mauriac C, Létard JF, Freysz E (2013) EPJ Web of Conferences 41: 05010.

Gawelda W, Johnson M, De Groot FMF, Abela R, Bressler C, Chergui M (2006) J. Am. Chem. Soc. 128: 5001-5009.

Gawelda W, Cannizzo A, Pham VT, van Mourik F, Bressler C, Chergui M (2007) J. Am. Chem. Soc. 129 8199-8206.

Gawelda W, Pham V-T, Benfatto M, Zaushitsyn Y, Kaiser M, Grolimund D, Johnson SL, Abela R, Hauser A Bressler C, Chergui M (2007) Phys. Rev. Lett. 98: 057401.
Gilbert B, Katz JE, Huse N, Zhang X, Frandsen C, Falconef RW, Waychunas GA (2013) Phys. Chem. Chem. Phys,15: 17303-17313.

Goswami N, Baksi A, Giri A, Xavier PL, Basu G, Pradeep Th, Pal SK (2014) Nanoscale 6: 1848-1854.

Goswami N, Chaudhuri S, Giri A, Lemmens P, Pal SK (2014a) J. Phys. Chem. C 118: 23434-23442.

Govindaiah P, Park T-J, Jung YJ, Lee SJ, Ryu DY, Kim KH, Cheong IW (2010) Macromol. Res. 18: 1109-1114.

Jabłoński A (1933) Nature 131: 839-840.

Jeremy E, McCusker JK (2000) J. Am. Chem. Soc. 122: 4092-4097.

Juban EA, Smeigh AL, Monat JE, McCusker JK (2006) Coord. Chem. Rev. 250: 1783-1981.

Khalil M, Marcus MA, Smeigh AL, McCusker JK, Chong HHW, Schoenlein RW (2006) J. Phys. Chem. A 110: $38-44$.

Kong QH, Liu H, Zhang YL, Yan YS (2011) Adv. Mat. Res. 391-392: 225-229.

Kramida A., Ralchenko Yu., Reader J., NIST ASD Team (2014): NIST Atomic Spectra Database (ver. 5.2), [Online]. Available: http://physics.nist.gov/asd, National Institute of Standards and Technology, Gaithersburg, MD.

Kulyuk LL, Laiho R, Lashkul AV, Lähderanta E, Nedeoglo DD, Nedeoglo ND, Radevici IV, Siminel AV, Sirkeli VP, Sushkevich KD (2010) Physica B 405: 4330-4334.

Marino A, Chakraborty P, Servol M, Lorenc M, Collet E, Hauser A (2014) Angew. Chem. Int. Ed. 53: 3863-3867.

McCusker JK, Walda KN, Dunn RC, Simon JE, Magde D, Hendricson DN (1992) J. Amer. Chem. Soc., 114: 6919-6920.

Monat JE, McCusker JK (2000) J. Amer. Chem. Soc. 122: 4092-4097.

Nasralla N, Yeganeh M, Astuti I, Piticharoenphun S, Shahtahmassebi N, Kompany A, Karimipour M, Mendis B, Poolton N, Šiller L (2013) Scientie Iranica F 20: 1018-1022.

Parsons R, Cornish WD, Young L (1975) Appl. Phys. Lett. 27: 654-655.

Podlowski L, Heitz R, Thurian P, Hoffmann A, Broser I (1994) J. Luminescence 58: 252-258.

Poznyakov IP, Plyusnin VF, Tkachenko N, Lemmetyinen H (2007) Chem. Phys. Lett. 445: 203-207.

Poznyakov IP, Plyusnin VF, Grivin VP, Vorobyev DY, Kruppa AI, Lemmetyinen H (2004) J. Photochem. Photobiol. A: Chem., 162: 153-162.

Poznyakov IP, Plyusnin VF, Grivin VP, Vorobyev DY, Bazhin NM, Vauthey E (2006) Photochem. Photobiol. A: Chem., 181: 37-43.

Poznyakov IP, Plyusnin VF, Grivin VP, Vorobyev DY, Bazhin NM, Pagés S, Vauthey E (2006) Photochem. Photobiol. A: Chem., 182: 75-81.

Rotman SR, Warde C, Tuller HL, Haggerty J (1989) J. Appl. Phys. 66: 3207-3210.

Sansonetti JE, Martin WC (2005) Handbook of Basic Atomic Spectroscopic Data. National Institute of Standards and Technology, Gaithersburg, MD 20899.

Sardar S, Sarkar S, Myint MTZ, Al-Harthi S, Dutta J, Pal SK (2013) Phys. Chem. Chem. Phys., 15: $18562-18570$

Sardar S, Kal P, Pal SK (2014) J. Mat. NanoSci. 1: 12-30. Šima J, Śípoš R, Szocs V (2013). In: (M. Melník, P. Segla, and M. Tatarko Eds.) Recent Developments in 
Coordination, Bioinorganic, and Applied Inorganic Chemistry (pp. 420-428), STU Press Bratislava.

Smeigh AL, Creelman M, Mathies RA, McCusker JK (2008) J. Am. Chem. Soc. 130: 14105-14107.

Turro NJ, Lakshminarasimhan PH, Jockusch PH, O'Brien S, Grancharov SP, Redl SG (2002), Nano Lett. 2: 325-328.

Varney RC, Reda SM, Mackay DT, Rowe MC, Selim FA (2011) AIP ADVANCES 1, 04217.0.
Vennekate H, Schwarzer D, Torres-Alacan J, Krahe O, Filippou AC, Neese F, Vöhringer P (2012) Phys. Chem. Chem. Phys. 14: 6165-6172.

Yam VW, Wong KM (2011) Chem Commun (Camb) 47: 11579-11592.

Yen WM, Shionoya S, Yamamoto H (2006) Fundamentals of Phosphors. CRC Press, Boca Raton, 257-259. 